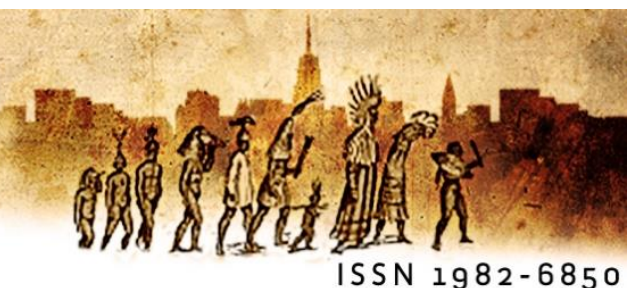

\title{
A consciência individual e o signo ideológico: uma leitura dos estudos de Volóchinov
}

\section{Individual consciousness and ideology: a reading of Volóchinov's studies}

Resumo: A consciência sobre 0 ato de ser no mundo passa pela curiosidade e por perguntas que colocam em jogo as palavras em confronto com a contrapalavra. Para responder às indagações, é necessário recorrer às formas simbólicas oriundas de diversos pontos de vistas que configuram significações sobre os referentes existentes na vida social. Nesse contexto, as palavras são sempre contornadas por gestos e entonações que revelam acentos apreciativos e juízo de valor. Dessa forma, a tomada de consciência de si e dos objetos que constituem a realidade é configurada nas interações sociais, sendo acessada por signos ideológicos. Tais relações podem ser melhor compreendidas se tomarmos como base os estudos de Volóchinov acerca da construção social dos signos ideológicos e de sua realização na consciência individual. Neste estudo de reflexão teórica, analisamos a construção do conceito de signo ideológico e a consciência individual sob a compreensão de Volóchinov (2013, 2017, 2019), considerando o seu diálogo com concepções do objetivismo abstrato e do subjetivismo individualista.

Palavras-chave: signo ideológico; consciência individual; ideologia; concepções de desenvolvimento de linguagem

\begin{abstract}
Awareness of the act of being in the world involves curiosity and questions that put words in confrontation with the counterword. To answer such questions it is necessary to resort to the symbolic forms from various points of view that configure meanings about the existing referents in social life. Therefore, words are always circumvented by gestures and intonations that reveal appreciative accents and value judgment. Thus, the awareness of oneself and the objects that constitute reality is configured in social interactions and accessed by ideological signs. Such relationships can be better understood if we take Volóchinov's studies on the social construction of ideological signs and their realization
\end{abstract}


in individual consciousness. In this study of theoretical reflection, we analyze the construction of the concept of the ideological sign and individual consciousness under the understanding of Volóchinov (2013, 2017, 2019) considering his dialogue with conceptions of abstract objectivism and idealistic subjectivism.

Keywords: ideological sign; individual awareness; ideology, conceptions of language development.

\section{Introdução}

Podemos afirmar que o ponto central da aprendizagem e do desenvolvimento humano é a consciência dos fenômenos físicos, ético-morais, culturais, sociais e históricos para realizar uma ação no mundo e se constituir como pessoa. Para explorar as representações construídas socialmente, o ser humano faz uso de sua percepção sensorial; podendo, então, organizar a sua experiência que sempre será cognitiva, social e afetiva-valorativa. Por esse ângulo, o indivíduo, de forma ativa e intuitiva, interioriza representações formuladas no espaço coletivo das trocas socioculturais e afetivas, as quais se manifestam de forma ideológica.

Para Schopenhaver (1985), o homem não conhece a realidade em si, mas explora de forma intuitiva os fenômenos, formulando representações derivadas de processos internos pelos quais busca conhecer a realidade externa e a si mesmo. Todo fato observado pode ser compreendido como um objeto que se enxerga uma pequena faceta do real, considerando o papel da percepção como forma de mediação e armazenamento de informações que torna possível o processo da significação. Existe, nesse contexto, a impossibilidade humana de tomar um fato, um fenômeno ou objeto em toda a sua plenitude. O que se consegue absorver é um conhecimento derivado da percepção que nos ajuda a compreender, em parte, a dinâmica de certos acontecimentos configurados a uma capacidade de percepção espacial e temporal existente a priori.

A percepção (direta e indireta) do "eu", em oposição aos objetos exteriores, que constitui o objeto dessa faculdade especial denominada percepção exterior. Esta última faculdade, ainda antes que se Ihe apresentem os objetos exteriores, possui certas formas necessárias (a priori) do conhecimento, formas que constituem, depois, outras tantas condições de existência para nós como objetos externos: tais são, como todos sabem, o tempo, o espaço, a causalidade. Mas, se bem essas formas da percepção exterior residam em nós, não têm elas, no entanto, outro fim que não seja o de permitir-nos adquirir conhecimento dos objetos exteriores como tais, em relação constante com as formas a elas pertinentes; desse modo, não devemos considerá-las como pertencentes ao domínio da consciência, mas, diversamente, como simples condições da possibilidade de todo conhecimento dos objetos exteriores, isto é, da sua percepção objetiva (SCHOPENHAUER, 1985, p.161). 
A compreensão dos fatos experenciados no mundo interior (psiquismo) e no espaço coletivo está, estreitamente, vinculada à percepção de tempo, de espaço e de causalidade que conduzem a relação do ser com outro no mundo por meio da linguagem. Sendo assim, o sujeito que interage no mundo é alguém que constrói uma identidade, tendo como base para conhecer as suas capacidades inatas que assimilam visões de mundo para responder os conflitos e as demandas que aparecem no plano das relações humanas, culturais, sociais e ideológicas. Tal relação ocorre, sempre pelo modo como a percepção dos objetos exteriores se apresentam, para dessa maneira deflagrar o desenvolvimento da consciência da realidade vivida.

No interior das transformações humanas, a língua participa dessa dinâmica de forma decisiva, na medida em que ela carrega consigo signos que revelam um conjunto de possibilidades virtuais de significação. Todavia, os sujeitos, quando ocupam o lugar de falante e usuário de uma língua, fazem escolhas individuais e coletivas que implicam a adoção de uma visão de mundo singular diante de discursos que inspiram visões de grupos sociais que os interpelam. Em uma perspectiva ampla, esse mecanismo demonstra que o sujeito tem autonomia relativa sobre o conteúdo do seu dizer no processo de interação. Conforme Bakhtin (2010), em um espaço mais imediato das relações humanas, o sujeito precisa assumir posicionamento moral e ético diante do outro e da experiência vivida. Sendo assim, existe uma dimensão da experiência individual no espaço da interação verbal que se consolida na relação com o outro para ampliar o desenvolvimento da consciência do sujeito no ato responsável de dizer e interagir.

Eu tomo consciência de mim e me torno eu mesmo unicamente me revelando para o outro, através do outro e com o auxílio do outro. Os atos mais importantes, que constituem a autoconsciência, são determinados pela relação com outra consciência (com o tu) (BAKHTIN, 2010, p.341).

Um ponto crucial desenvolvido nos estudos de Bakhtin foi a compreensão da tomada de consciência do sujeito toda vez que este assume uma voz responsiva em suas interações verbais no plano da eventicidade. O modo de agir, numa relação de alteridade, promove a consciência de si e do outro em espaços coletivos que possuem suas regras cognitivas, sociais e culturais.

Podemos dizer, também, que a consciência tem uma materialidade pré-construída pelas experiências coletivas que dialogam com o discurso interior do sujeito que interage. Neste universo, fazemos algumas reflexões sobre o processo de formação da consciência humana e o processo de transformação da linguagem no seio de uma coletividade, considerando a mediação da linguagem e as experiências dos sujeitos no ato de produção de um enunciado. Para isso, 
revistamos os postulados defendidos por Valetin Volóchinov (1895-1936) em seu livro "Marxismo e Filosofia da Linguagem" publicado em 1929, em Lenigrado.

Essa obra concentrou-se na compreensão do papel da linguagem no psiquismo humano, ou seja, na constituição do discurso interior, como um fenômeno interno mediado por signos ideológicos que se sustentam por vozes sociais que ecoam na formação dos discursos produzidos pelo sujeito na sociedade. Do mesmo modo, a obra investiga as relações da formação ideológica atrelada à produção de enunciados ditos por sujeitos responsivos que revelam, em seus enunciados, acentos apreciativos sobre os temas proferidos, sempre configurados a determinadas condições econômicas, sociais, culturais e interacionais que revelam uma experiência irrepetível com o outro no ato de enunciar.

\section{As críticas ao subjetivismo individualista e ao objetivismo abstrato}

Para propor um método de estudo sociológico sobre o funcionamento da linguagem na dinâmica da interação discursiva, Volóchinov (2017) faz uma ampla revisão dos estudos da linguagem no campo da filosofia da linguagem, da estilística e da linguística, identificando duas tendências que tentam explicar as transformações das línguas e as suas formas de apropriação. A primeira tendência, sustentada no pensamento idealista, concebe o sujeito como fonte de conhecimento, pressupondo a ideia de que a língua é uma substância de ordem subjetiva, criativa e individual.

Um dos representantes dessa tendência, denominada subjetivismo individualista, foi Karl Vossler (1872-1949). Ele atuou como professor de Linguística, Teoria da Literatura e Filologia na Universidade de Munique, Alemanha. Aprofundou os conceitos da estilística e da filosofia da linguagem idealista, sendo influenciado por Wilhelm Von Humboldt e Benedetto Croce, que defenderam postulados do pensamento subjetivista sobre a criação da linguagem.

Vossler (1968), em oposição ao pensamento positivista, fez uma série de reflexões sobre o desenvolvimento das línguas de diferentes nações, demonstrando que cada nação busca formas expressivas na língua para representar suas ideias. Para este pensador, a essência de toda língua era dinâmica, sendo renovada por formas poéticas criativas de natureza artística derivada do espírito de época vivido por um povo. Dessa forma, o fator cultural concebido por uma coletividade, no âmbito artístico, corresponde a uma força vital transformadora da língua. Toda 
criação linguística se apoia em um conjunto de formas simbólicas artísticas e culturais formuladas no seio de uma coletividade de forma expressiva e criativa.

De acordo com Grillo (2017), Vossler é dotado de um pensamento ambivalente, visto que assume uma segunda faceta para explicar as transformações da língua, em decorrência da disposição transformadora do próprio sistema linguístico em seu uso. Para esse pensador, a língua também é vista como um produto autônomo de caráter gramatical a qual pode ser compreendida pela configuração de suas regras e de suas leis de funcionamento. Muitas transformações de ordem vocabular e sintática podem ser explicadas com base na descrição das regras e das leis que apontam para tendências de realização da língua de maneira econômica no processo de interação. Sendo assim, Vossler defende que a evolução de certas formas linguísticas não é de ordem histórica, mas é determinada pela tendência econômica dos falantes suprimirem ou transformarem certas estruturas linguísticas no percurso de seu uso.

Relativizando o ponto de vista de Vosller, Grillo (2017) afirma que o linguista não desconsidera a existência de questões histórico-culturais que também contribuam para a evolução das formas linguísticas, como: a) empréstimos de uma língua estrangeira, b) formulações de usos linguísticos adotados em uma determinada esfera de atividade humana, e c) o uso de gírias e variantes regionais. Vossler considera a gramática o eixo do sistema linguístico, fruto de convenções; tendo, portanto, um papel decisivo na formação e na transformação de uma língua. Grillo (2017) observa a preocupação do filósofo-linguista e situar o lugar da gramática na história de uma língua como uma série intermediária. Para Vossler, na história da língua, haveria dois polos: a série gramatical pura e a série da história cultural. Entre elas, era possível reconhecer uma série gramatical intermediária.

\footnotetext{
A história gramatical é uma série intermediária a ligar a série puramente gramatical à série histórico-cultural; portanto, a história da língua insere-se na ciência geral da cultura. No entanto, Vossler defende que a história da língua tem sua própria inclinação: a de apoiar-se na história da arte e, em especial, da literatura (GRILLO, 2017, p. 37).
}

Apesar de considerar alguns aspectos socioculturais na proposta de estudo da linguagem de Vossler, é possível perceber que a sua perspectiva adota uma visão subjetivista, calcada na psicologia individual. Predomina, na visão Vossler, o papel da criatividade linguística no desenvolvimento da linguagem de uma coletividade, notada, principalmente, pelas contribuições artísticas da literatura. As transformações da língua e da consciência decorrem, então, das ações 
criativas do espírito de um povo ou das atividades artísticas recriadoras das formas de dizer, modificando, consequentemente, o modo de conceber o mundo. Tal tendência subjetivista individualista é bastante questionada por Volóchinov (2017), pois sustenta a falsa ideia de que os fenômenos da linguagem e da consciência são determinados por leis de expressão individual ou do espírito de um povo em dado momento histórico. De acordo com esse pensador, as explicações assumidas por essa perspectiva se voltam para a ideia de um sujeito psicológico desvinculado da realidade social e cultural.

Ao fazer essa analogia entre a criação linguística e a criação artística, tem-se o indivíduo como o senhor do discurso. Com isso há destaque somente para a psique do sujeito, rejeitando totalmente o fator social como agente influenciador na enunciação. Nessa teoria, encontramos a enunciação como resultado da expressão da consciência individual, sendo, nesse caso, como um espelho do que o falante traz na sua psique (SILVA; LEITE, 2013, p.40).

A segunda tendência é construída sob a égide do objetivismo, que busca descrever e compreender os fatos da linguagem por meio da observação de fatos concretos manifestados na realidade. Essa corrente procura observar um sistema de regras e normas estáveis, como produto acabado, determinantes ao desenvolvimento da linguagem e ao seu funcionamento. Um dos principais representantes dessa abordagem é Saussure, que vê a língua como um sistema de signos arbitrários responsável pelo processo de significação por meio de um processo de oposição das unidades linguísticas

Volóchinov (2017) questiona a possibilidade de se estudar os mecanismos de significação fora da interação verbal. Ele propõe a construção de um método sociológico de estudo da linguagem fundamentado em procedimentos de uma dialética histórico-marxista na qual se discuta a materialidade do signo verbal na relação interindividual, social e histórica. Contrapondose à visão de Saussure, que via as unidades linguísticas de forma homogênea e abstrata no interior das frases; Volóchinov defende a natureza social nos estudos da linguagem, destacando o lugar da fala e dos sujeitos na construção do signo no ato de sua realização. Com isso, o filósofo procura desenvolver a teoria do enunciado concreto na vida cotidiana, considerando a questão da formação ideológica na constituição da linguagem e na formação da consciência humana.

Para romper com a visão determinista do materialismo histórico visto de maneira mecanicista, Volóchinov (2017) examina estudos sobre a formação ideológica e das consciências vinculados às condições econômicas, sociais e históricas. Seus estudos problematizam o modo como a noção de ideologia foi compreendida pela psicologia social e abordagens centradas nas 
relações de classe. Muitas explicações sobre o funcionamento da ideologia não levavam em conta o papel da mediação da linguagem e as formulações subjetivas.

Na leitura do materialismo histórico, visto de forma mecânica e determinista, defendia-se que as formas de pensar eram oriundas de um conjunto de representações e ideias de quem detinha o poder econômico. Aqueles que dominavam os bens de produção e compravam a força de trabalho não só dominavam a base econômica como também manipulavam as construções simbólicas. Nessa visão, as instituições sociais como a escola, a igreja, os meios de comunicação e a comunidade científica assumem o papel de reproduzir a ideologia das classes dominantes. Seguindo esse postulado, as formações ideológicas derivavam das relações promovidas pela superestrutura (base econômica) e da infraestrutura (instituições que mantêm as normas: família, igreja, escola, justiça, meios de comunicação etc.), responsáveis pela manutenção do sistema de exploração capitalista. Dessa forma, a ideologia, para os marxistas, era vista como uma falsa consciência reproduzida por instituições como a igreja para disseminar dogmas que coloca o homem em uma posição de alienação.

Até agora, os homens sempre tiveram ideias falsas a respeito de si mesmos, daquilo que são ou deveriam ser. Organizaram suas relações em função das representações que faziam de Deus, do homem normal etc. Esses produtos de seu cérebro cresceram a ponto de dominá-los completamente. Criadores, inclinaramse diante de suas próprias criações. Livremo-los, pois, das quimeras, das ideias, dos dogmas, dos seres imaginários, sob o jugo dos quais eles se estiolam. Revoltemo-nos contra o domínio dessas ideias. Ensinemos os homens a trocar essas ilusões por pensamentos correspondentes à essência do homem, diz alguém; a ter para com elas uma atitude crítica, diz outro; a tirá-las da cabeça, diz o terceiro e; a realidade atual desmoronará. (MARX e ENGELS, 1998, p. 3)

Marx e Engels (1998) reconhecem a criação ideológica com foco na produção simbólica das instituições (ciência, literatura, religião) que determinam a percepção da realidade. Todavia, o modo como descreve o processo de criação ideológica é visto de maneira estreita, pois concentrase nas relações do trabalho e no conjunto de ideias difundidas pelas instituições vinculadas ao o estado. Cumpre as instituições controladas pelo estado reproduzir as ideologias dominantes. Marx e Engels demonstram que existe um ocultamento e uma inversão de valores na representação dos fatos concretos da vida cotidiana, ignorando-se a existência das lutas de classe e a exploração do trabalhador. Sob essa perspectiva, Marx e Engels, em 1848, defendem a ruptura com a ideologia da classe dominante por meio da conscientização da massa trabalhadora. O objetivo desses pensadores foi modificar as relações de exploração do trabalho alheio e a lógica de produção 
capitalista que vive da mais-valia, deixando o operário à margem da sociedade. Sob essa perspectiva, a consciência é um produto social, que se mantém pelas condições materiais da existência, determinada pela divisão do trabalho e a distribuição dos bens de consumo.

A consciência empreende isoladamente; toda essa podridão só nos dá um resultado: esses três momentos - a força produtiva, o estado social e a consciência - podem e devem entrar em conflito entre si, pois, pela divisão do trabalho, tornase possivel, ou melhor, acontece efetivamente que a atividade intelectual e a atividade material - o gozo e o trabalho, a produção e o consumo - acabam sendo destinados a indivíduos diferentes; então, a possibilidade de esses elementos não entrarem em conflito reside unicamente no fato de se abolir novamente a divisão do trabalho. É evidente aliás que os "fantasmas", "laços", "ser supremo", "conceito", "escrúpulos" são apenas a expressão mental idealista, a representação aparente do indivíduo isolado, a representação de cadeias e de limites muito empíricos no interior dos quais se move o modo de produção da vida e o modo de trocas ligado a ele. (MARX e ENGELS, 1998, p. 27)

Marx e Engels demonstram que a função da ideologia seria a manutenção das relações de poder da classe dominante, atuando de forma manipuladora e dissimuladora; ocultando, assim, os fatos da realidade. O Estado, sendo o difusor da cultura oficial, defenderia os ideais e os projetos da classe possuidora dos bens de produção. Para compreender a ideologia, por meio das concepções de mundo construídas, é preciso observar as condições materiais de subsistência do homem em uma sociedade e os processos de produção do mundo do trabalho.

Apesar desses estudos serem de grande importância para a compreensão da formação da consciência e da ideologia, Volóchinov relata que a noção de ideologia nos estudos marxistas não destaca o papel da linguagem como fonte mediadora de construção das ideias no campo da experiência individual na esfera da vida cotidiana. A psicologia social, de base marxista, explica a transformação do homem pelas atividades que realiza no mundo do trabalho; fator que geraria uma consciência de si na medida em que acumula formas de conhecimento compartilhados, ou seja, o homem modifica a natureza e as condições materiais e essas modificam a sua natureza. Volóchinov aponta para a ampliação dessa visão, ressaltando as contribuições do poder simbólico da linguagem na construção da consciência, considerando as relações subjetivas da experiência humana particular mediada pela língua. Por conseguinte, são incluídas reflexões da filosofia da linguagem sobre o desenvolvimento da consciência humana e a compreensão dos enunciados ideológicos.

Até o presente momento, ainda não existe nenhum trabalho marxista sobre a filosofia da linguagem. Mais do que isso, não há nenhum enunciado preciso e bem 
desenvolvido sobre a linguagem nos textos de orientação marxista dedicados a temas semelhantes. Portanto, é bem compreensível que, por ser de fato pioneiro, nosso trabalho possa abordar apenas as tarefas mais modestas. (VOLÓCHINOV, 2017, p.83)

Volóchinov (2017) considera que as formas de produção ideológica podem ser explicadas para além da linha de reprodução dos valores disseminados pelas classes dominantes nas esferas oficiais, uma vez que a força das interações verbais realizadas nas esferas cotidianas pode promover construção de novas ideias nos diferentes espaços: artístico, cultural e político. Sendo assim, a ideologia não se manifesta somente nas relações determinadas pela base econômica com a superestrutura, mas em todas as relações perpassadas por atividades simbólicas realizadas por um indivíduo e uma coletividade.

Volóchinov (2017) critica o materialismo mecânico pré-dialético, que tenta explicar a realidade por relações de causalidade mecânica em todas as áreas da ciência seduzida pelo positivismo. Na maioria das análises sobre a formação ideológica, não se fala dos processos subjetivos, dos afetos e das relações que vão para além da esfera das forças de produção. Em abordagens mecanicistas do materialismo pré-dialético, considera-se que o mundo do trabalho modela o comportamento dos seres humanos, determinando seu modo de agir e de pensar.

\section{A consciência individual e a construção do signo ideológico (sinal, símbolo e signo)}

A grande contribuição de Volóchinov $(2017,2019)$ é a reflexão sobre a construção do signo ideológico no processo de representação dos objetos pela via da interação verbal e o desenvolvimento da consciência individual. Para entender esse processo, o estudioso da linguagem apresenta reflexões sobre o modo como os signos são formulados na sociedade e na consciência individual. Um objeto-referente em si no mundo não tem significação ampla, visto que ele compõe simplesmente um traço da realidade natural. Um referente só ganha sentido quando ele sobrevém de um processo de apreciação e juízo de valor realizado por um grupo de pessoas ou indivíduos numa dada coletividade. Para compreender o processo de construção ideológica, é preciso considerar os objetos da vida material sob duas formas: uma do ponto de vista de um referente na vida material, tendo uma significação imutável; e a segunda que aponta 
para a construção de signos que assumem valor simbólico carregados de acento apreciativo. Isso posto, todo objeto, representado por um signo, é avaliado e apreciado por um grupo que promove juízos de valor carregado de vivência e história. É nesse momento que se vincula o processo de criação ideológica a uma dinâmica axiológica-volitiva-emotiva que se manifesta por meio da linguagem.

Volóchinov (2019) alerta que os objetos da vida cotidiana e os fenômenos da natureza, a princípio, não carregam significação ideológica. Podemos observar, em diferentes coletividades, a passagem de muitos objetos ao estado de signos ideológicos pela realização de mecanismos simbólicos. Isso aconteceu, por exemplo, com os alimentos o pão e o vinho que se transformaram em símbolos da religião cristã, remetendo à ideia de comunhão do homem com Deus. O pão deixou de ser visto como simples objeto de consumo alimentar e passou a representar um conjunto de ideias que remetem à visão do mundo bíblico. Nesse enquadramento, o pão ganha estatuto de signo com a propriedade de refletir e refratar a realidade. Da mesma forma, aconteceu com os instrumentos de produção o martelo e a foice que se tornaram emblema da bandeira da União Soviética. Tais ferramentas, na bandeira, correspondem a símbolos da pátria soviética que conotam as figuras do operário das fábricas e do camponês como representantes da força produtiva do país, convertendo-se, assim, em signos ideológicos.

Qualquer objeto da natureza, da tecnologia ou de consumo pode se tornar um signo. Neste caso, porém, ele irá adquirir uma significação que ultrapassa suas próprias particularidades. Um signo não existe apenas como parte de os limites de sua existência particular. O signo não é somente uma parte da realidade, mas também reflete e refrata uma outra realidade, sendo por isso mesmo capaz de distorcê-la, ser-lhe fiel, percebê-la de um ponto de vista específico e assim por diante. As categorias de avaliação ideológica (falso, verdadeiro, correto, justo, bom, etc.) podem ser aplicadas a qualquer signo. O campo ideológico coincide com o campo dos signos. Eles podem ser igualados. Onde há signo há também ideologia. Tudo o que é ideológico possui significação sígnica. (VOLÓCHINOV, 2017, p. 93).

Interessa a Volóchinov (2019) analisar como os signos em uma realidade enunciativa construída de forma ideológica, considerando o lugar da consciência individual no ato de sua realização. O signo, por carregar uma orientação subjetiva, pode refletir e refratar a realidade, visto que todo referente traz na sua constituição a apreciação de quem formula uma representação com base em sua experiência individual e coletiva. Opondo-se às formas linguísticas abstratas saussurianas dotadas de significado monológico, com palavras em estado de dicionário, sob a forma de sinal; os signos ideológicos têm como princípio a réplica a outros signos, 
opondo-se a um gesto de compreensão passiva. Toda atividade com o signo; realizada em uma esfera artística, científica e cotidiana; assume uma perspectiva compreensiva ao retratar e compreender a realidade.

Nesse cenário, Volóchinov (2017) afirma que os símbolos não-verbais podem ser concebidos na forma de músicas, de rituais religiosos e quadros de artistas com a função de expressar sentimentos e impressões da vida social e cultural. Toda forma artística, embora não se construa por formas linguísticas em sua camada superficial, pode ser concebida como signos nãoverbais responsáveis por formulações ideológicas. Os símbolos, enquanto elementos visuais e sonoros, são organizados dentro de um sistema de representação que não podem ser substituídos por signos verbais, todavia as palavras apoiam o seu processo de significação. Nesse caso, essas imagens, estruturas simbólicas, chegam ao nosso nível de compreensão com auxílio da palavra na medida em que esse conjunto de signos não-verbais entram em diálogo com o discurso verbal. Observarmos que os signos não-verbais podem ser compreendidos como formas simbólicas que possuem uma materialidade, no interior de um sistema fechado (algébrico, artístico), projetandose no discurso interior com no que é dito sobre essas obras no discurso verbal.

Já as palavras podem ser utilizadas em diferentes campos das esferas sociais de forma flexível, conferindo um espaço de reconfiguração contínua no plano de sua semiotização. Alertase que as palavras correspondem à matéria-prima essencial do discurso interior, podendo as imagens acústicas ou visuais retroalimentarem o universo dos signos ideológicos. Volóchinov destaca o valor das palavras como signos ideológicos por excelência. Toda palavra ocupa a função de signo em uma atividade sociocomunicativa, correspondendo a um meio sensível e material funcional para formular pensamentos e ideologias.

Para o entendimento da palavra como signo por excelência, é preciso descontruir a noção da língua como um sistema de formas linguísticas abstratas que assume a forma de sinal. Para Volóchinov (2017), o sinal é um elemento linguístico que remete a um objeto imóvel, invariável e unitário correspondente a um meio técnico que visa ao reconhecimento de estruturas semânticas. Os sinais são mobilizados por meio da decodificação, extraindo um valor abstrato das palavras. Sendo assim, as palavras, como sinais, não ganham conotação ideológica, visto que não se realizam por meio de sujeitos concretos que movimentam a língua, criando sentidos particulares. Já os signos ideológicos referem-se a usos concretos das palavras que atuam sobre a consciência individual e dos grupos sociais em relação dialética. A compreensão dos signos ideológicos, material semiótico do discurso interior, aponta para o desenvolvimento das consciências no seio 
de grupo social, considerando a experiência individual de cada falante no processo de interação verbal.

\begin{abstract}
A consciência não pode ser deduzida diretamente da natureza, como tentava e ainda tenta fazer o materialismo mecanicista ingênuo e a psicologia objetiva atual (biológica, behaviorista e reflexológica). A ideologia não pode ser deduzida a partir da consciência, como fazem o idealismo e o positivismo psicológico. A consciência se forma e se realiza no material sígnico criado no processo da comunicação social de uma coletividade organizada. A consciência individual se nutre dos signos, cresce a partir deles, reflete em si a sua lógica e as suas leis. A lógica da consciência é a lógica da comunicação ideológica, da interação sígnica de uma coletividade. Se privarmos a consciência do seu conteúdo sígnico ideológico, não sobrará absolutamente nada dela. A consciência apenas pode alojar-se em uma imagem, palavra, gesto significante etc. Fora desse material resta um ato fisiológico puro, não iluminado pela consciência, isto é, não iluminado nem interpretado pelos signos (VOLÓCHINOV, 2017, p.97-98).
\end{abstract}

Volóchinov (2017) critica a visão subjetivista defendida pelo psicologismo, que desconsidera a exterioridade e a materialidade dos objetos construídos socio-históricamente por meio dos signos. O desenvolvimento da consciência passa pela mediação da matéria semiótica que se manifesta por meio de signos ideológicos. Os signos se organizam para formular representações no espaço da interação social. Por outro lado, nenhum signo corresponde à retomada de um já dito, visto que as experiências vividas pelos sujeitos transformam as representações mediadas pelos signos. Sendo assim, a linguagem não é um simples reflexo das condições sociais, mas sim fruto de constantes embates no plano das interações entre consciências.

\title{
A construção do signo inferno no romance Vidas Secas pelo personagem Menino mais Velho
}

A fim de ilustrar o processo dialógico e o desenvolvimento da consciência individual por meio da internalização dos signos ideológicos no processo de interação social, utilizamos o capítulo VI- O Menino Mais Velho do romance Vidas Secas do alagoano Graciliano Ramos (18921953), publicado em 1938. Podemos identificar, nesse texto, personagens solitários que apresentam dificuldade de dialogar, isto é, realizar trocas verbais voltadas para ampliação do universo existencial deles. A narrativa tem como núcleo central uma família de retirantes da seca do nordeste composta por um vaqueiro chamado Fabiano, sua esposa Sinhá Vitória, uma cachorra chamada Baleia, um papagaio e dois filhos designados de Menino mais Novo e de Menino mais 
Velho. Os filhos não possuem nome próprio, afastando a possibilidade de construção de uma identidade com uma palavra que os nomeiem. O romance, contado em $3^{\text {a }}$ pessoa, relata acontecimentos da migração de uma família fugindo da seca, com a intercalação do discurso interior dos personagens que expõem suas impressões subjetivas diante de acontecimentos vinculados à sobrevivência, aos sonhos e aos questionamentos diante dos sofrimentos causados pela seca do sertão. No capítulo VI, temos como foco central a figura do Menino mais Velho que deseja saber o significado da palavra inferno.

Podemos perceber que o Menino mais Velho é descrito como alguém com um vocabulário restrito e minguado, parecido com o do papagaio que tinha morrido durante a peregrinação. $O$ garoto se valia de pequenos gestos e expressões verbais para realizar posicionamentos afetivos e valorativos diante do vivido. Na maioria das vezes, seu interlocutor mais próximo era a cachorra, Baleia, que respondia balançando o rabo.

Como não sabia falar direito, o menino balbuciava expressões complicadas, repetia as sílabas, imitava os berros dos animais, o barulho do vento, o som dos galhos que rangiam na caatinga, roçando-se. Agora tinha tido a ideia de aprender uma palavra, com certeza importante porque figurava na conversa de Sinha Terta. la decorá-la e transmiti-la ao irmão e à cachorra. Baleia permaneceria indiferente, mas o irmão se admiraria, invejoso.

- Inferno, inferno. (RAMOS, 1993, P.57).

Um gatilho que desencadeia a curiosidade do Menino mais Velho pelo significado da palavra inferno foi o encontro com uma curandeira. O garoto viu a benzedeira, Sinha Terta, fazer uma reza para curar as chicoteadas que Fabiano tomou na cadeia, sussurrando a palavra inferno com entonação agradável. A palavra inferno ganhou valor positivo, pois foi assimilada como um índice da reza capaz de curar as feridas do pai. O signo assume as duas faces de Jano, apresentando um significante de expressão acústica e um tema expandido pelos acontecimentos e pelas vozes que falam sobre o inferno.

Impulsionado pela curiosidade, o Menino mais Velho pergunta à mãe, Sinha Vitória, o significado da palavra inferno, e ela the responde de forma vaga que era um lugar ruim. Não satisfeito com a resposta da mãe, pergunta ao pai, que nada lhe responde. O menino percebe que a palavra para os pais não tem o mesmo sentido assimilado por ele quando viu a reza de Sinha Terta. Insatisfeito com a resposta abreviada da mãe, o menino retorna e pergunta: "Como é ?". A mãe responde que é um lugar que tem fogueira e espeto quente. O filho não convencido, retruca "Você já viu?". Tal indagação gerou indignação da mãe, conferindo uns cascudos no menino. 
Nessa ocasião, podemos acompanhar o discurso interior do menino que desconfia do discurso autoritário.

Não acreditava que um nome tão bonito servisse para designar coisa ruim. E resolvera discutir com Sinha Vitória. Se ela houvesse dito que tinha ido ao inferno, bem. Sinha Vitória impunha-se, autoridade visível e poderosa. Se houvesse feito menção de qualquer autoridade invisivel e mais poderosa, muito bem. Mas tentara convencê-lo dando-lhe um cocorote, e isto lhe parecia absurdo. Achava as pancadas naturais quando as pessoas grandes se zangavam, pensava até que a zanga delas era a causa única dos cascudos e puxavantes de orelhas. Esta convicção tornava-o desconfiado, fazia-o observar os pais antes de se dirigir a eles. (RAMOS, 1993, p.58).

Nesse trecho, podemos observar o monólogo interior do menino na tentativa de construir o significado do signo inferno e ao mesmo tempo em que começa a duvidar da voz social dos pais. O processo de tomada de consciência da realidade vivida fez o menino contrastar a voz da Sinha Terta, a voz de Sinha Vitória e o comportamento silencioso de seu pai. No discurso interior do menino, é possível observar a construção de hipóteses sobre o modo como cada voz estabelece uma representação para o signo inferno. Aos poucos, o menino toma consciência da sua própria condição de vida na seca e do mau trato familiar, tentando entender a visão figurativa de lugar com fogueira e espeto quente que a mãe chama de inferno. A voz interior do menino, por meio do discurso indireto livre, é colocada em destaque. "Talvez Sinha Vitória dissesse a verdade. O inferno devia estar cheio de jararacas e suçuaranas, e as pessoas que moravam lá recebiam cocorotes, puxões de orelhas e pancadas com bainha de faca. " (RAMOS, 1993, p.60).

Vemos que o signo inferno é tecido com uma aglomeração de fios de sentidos para refletir e refratar a realidade do menino. Para o menino, o inferno era o lugar com animais ameaçadores, seco e quente como o lugar onde morava, acompanhado da violência doméstica sofrida quando se perguntava alguma coisa. Aqui não temos uma palavra que opera como um sinal na qual se busca um significado em estado de dicionário, mas palavras em confronto com a realidade exterior que alimentam a consciência interior. Desse modo, a palavra inferno não se reverte em um símbolo religioso dotado de significado pleno no interior de um sistema fechado alegórico no qual cada índice tem um significado próprio. A palavra inferno, como signo ideológico, corresponde a um conjunto de tensões presente no processo da interação social na existência de um eu encarnado. A sua possibilidade de significação se estende para além de sentidos convencionalmente aceitos socialmente. Dessa forma, cada um tem a sua imagem e a sua percepção de inferno registradas na sua consciência individual. 


\section{Considerações finais}

Podemos observar que o filósofo da linguagem Volóchinov apresenta uma visão crítica sobre duas vertentes que vigoravam nos estudos sobre o desenvolvimento da consciência e da ideologia. A primeira tendência subjetivista aponta para explicações de ordem psicológica ou para uma concepção positivista e idealista do desenvolvimento da linguagem. Nessa abordagem se valoriza o processo criativo de quem utiliza a língua, encarando-a como expressão individual determinada por formas artísticas (subjetivismo individualista); já a segunda, concebe a língua como um sistema estável de formas pré-concebidas que determina as formas de agir e pensar sobre a realidade (objetivismo abstrato). Essas duas abordagens não reconhecem, de forma satisfatória, a importância da mediação dos signos em enunciados concretos e da vivência para descrever o desenvolvimento da consciência e refletir o processo de transformação dos usos da língua no curso da história e na interação face a face pelos sujeitos que mobilizam a língua. Dessa forma, Volóchinov faz a seguinte síntese sobre a noção de língua em concepção sociológica.

1. A língua como sistema estável de formas normativas e idênticas é somente uma abstração científica produtiva apenas diante de determinados objetivos práticos e teóricos. Essa abstração não é adequada à realidade concreta da língua.

2. A língua é um processo ininterrupto de formação, realizado por meio da interação sociodiscursiva.

3. As leis da formação da língua não são, de modo algum, individuais e psicológicas, tampouco podem ser isoladas da atividade dos indivíduos falantes. As leis da formação da língua são leis sociológicas em sua essência.

4. A criação da língua não coincide com a criação artística ou com qualquer outra forma de criação especificamente ideológica. No entanto, ao mesmo tempo, a criação linguística não pode ser compreendida sem considerar os sentidos e os valores ideológicos que a constituem. A formação da língua, como qualquer formação histórica, pode ser percebida como uma necessidade mecânica cega, porém também pode ser uma "necessidade livre" ao se tornar consciente e voluntária.

5. A estrutura do enunciado é uma estrutura puramente social. O enunciado como tal existe entre os falantes. $O$ ato discursivo individual (no sentido estrito do termo "individual") é um contradictio in adjecto. (VOLÓCHINOV, 2017 [1929], p. 225).

Ao considerar o signo como elemento mediador da consciência e da formação ideológica, Volóchinov rompe com a noção de língua como objeto de significação que se realiza de forma neutra e descontextualizada das condições de interação social. Defendendo um método 
sociológico de linguagem, com base em uma perspectiva histórico-dialética marxista, o pesquisador avalia as ideias do subjetivismo individualista e do objetivismo abstrato, promovendo uma síntese do entendimento do que seja língua, linguagem, enunciado, signo, formação da consciência e da ideologia. Para reconhecer o sentido ideológico da palavra, é preciso observar a orientação da palavra entre interlocutores no processo dialógico.

O significado da orientação da palavra para o interlocutor é de excepcional importância. Em substância, a palavra representa um ato bilateral. Ela vem determinada em igual medida seja de quem ela provém quanto a quem ela é dirigida. Esta é uma palavra própria enquanto produto de uma relação recíproca entre falante e ouvinte. Qualquer fala exprime "um" na relação com "o outro". No falar eu me conformo ao ponto de vista de um outro, ou seja, em última instância, ao ponto de vista da comunidade a que pertenço. A palavra é uma ponte lançada entre mim e os outros. Se uma extremidade desta ponte se apoia sobre mim, a outra se apoia sobre meu interlocutor. A palavra é o território comum existente entre o falante e o interlocutor. (VOLOCHINOV, 2013, p.127).

Por meio da exposição dos postulados defendidos pelas abordagens teóricas subjetivistas e objetivistas, Volóchinov estabelece contrapontos, organizando uma nova síntese para refletir sobre a formação da consciência e o processo de interação verbal mediados por signos ideológicos que estão sempre em processo de construção. Para demonstrar o seu raciocínio e esclarecer suas ideias, o autor aprofunda a discussão sobre o processo de significação da linguagem, considerando-o em situações concretas. O signo é concebido como ideológico e de natureza interindividual.

Volóchinov (2017) toma o enunciado como um evento em que a língua se comporta de forma dinâmica na troca verbal entre sujeitos situados no espaço social e subjetivo. Nessa perspectiva, o enunciado se constitui de elementos verbais e não verbais em um processo catalisador de construção de sentidos, sendo composto por objetos simbólicos de distintas ordens (palavras, gestos, expressão facial, entonações, imagens, dentre outras). Seguindo a linha de raciocínio, os processos de significação podem ser recuperados ou retomados, em parte, numa nova interlocução, mas nunca repetidos, de forma idêntica, em uma nova circunstância.

Diante da representação literária de Vidas Secas, tivemos a oportunidade de notar como uma criança desenvolve a sua percepção da realidade por meio da vivência com o mundo exterior e com a linguagem, buscando pistas para assimilar as ideias acerca do signo inferno. Acompanhamos a construção do signo inferno a partir do encontro com Dona Terta, que pronuncia a palavra em contexto de cura. A experiência da palavra inferno vivida no terreiro é colocada em confronto com os dizeres de Sinhá Vitória associados ao discurso da igreja Católica. 
Essas visões de mundo perpassam o processo de construção do signo ideológico construídos a partir das vozes sociais junto às experiências vividas. Nesse sentido, todo signo é uma arena de disputa de sentidos, colocando a língua e a percepção da realidade exterior para além de uma estrutura semântica. O signo se configura como mola propulsora de construção de identidades e de discursos, mas sempre em contraste com a vivência de quem constrói as representações. Acreditamos que essa visão defendida por Volóchinov (2013, 2017, 2019) apresenta um conjunto de procedimentos que nos permite olhar a linguagem como uma atividade dialética na qual o social e o individual estão em constante tensão para dinamizar as interações sociais e criar espaços de representação e compreensão entre as consciências individual e coletiva.

\section{Referências bibliográficas}

BAKHTIN, M. M. [1920]. Para uma filosofia do ato responsável. Tradução aos cuidados de Valdemir Miotello e Calos Alberto Faraco. São Carlos: Pedro \& João Editores, 2010.

GRILLO, Sheila. Marxismo e Filosofia da linguagem: uma resposta à ciência da linguagem do século XIX e início do XX. Ensaio introdutório. In VOLÓCHíNOV, V. N. (círculo de Bakhtin). Marxismo e filosofia da linguagem. Problemas fundamentais do método sociológico na ciência da linguagem. Trad. Sheila Grillo e Ekaterina Vólkova Américo. 1. ed. São Paulo: Editora 34, 2017.

MARX, K.; ENGELS, F. A ideologia alemã. Tradução de Luiz Cláudio de Castro e Costa. São Paulo: Martins Fontes, 1998.

RAMOS, G. Vidas secas. Rio de Janeiro: Record, 1993.

SAUSSURE, Ferdinand de. Curso de Linguística Geral. São Paulo: Cultrix, 1995.

SILVA, Danielle Sousa; LEITE, Francisco de Freitas. O subjetivismo idealista e o objetivismo abstrato no Círculo de Bakhtin. Miguilim - Revista Eletrônica do Netlli, Crato, v. 2, n. 2, p. 38-45, ago. 2013 .

SCHOPENHAUER, Arthur. O livre arbítrio In: Os maiores clássicos de todos os tempos. Vol. III. Editora Novo Horizonte. 1985, p. 161-166.

VOSSLER, Karl. Filosofía del lenguaje. Trad. Amado Alonso y Raimundo Lida. 5. ed. Buenos Aires: Editorial Losada S.A., 1968.

VOLÓCHINOV, V. N. (círculo de Bakhtin). Marxismo e filosofia da linguagem. Problemas fundamentais do método sociológico na ciência da linguagem. Trad. Sheila Grillo e Ekaterina Vólkova Américo. 1. ed. São Paulo: Editora 34, 2017.

VOLÓCHINOV, Valentin. A palavra na vida e a palavra na poesia: ensaios, artigos, resenhas e poemas / Valentin Volóchinov; organização, tradução, ensaio introdutório c notas de Sheila Grillo e Ekaterina Vólkova Américo — São Paulo: Editora 34, 2019.

VOLOCHÍNOV, V. N. (Do Círculo de Bakhtin). A construção da enunciação e outros ensaios. Org., Trad., Notas João Wanderley Geraldi. São Carlos: Pedro \&João Editores, 2013. 


\footnotetext{
' Professor associado do Departamento de Letras Vernáculas da Universidade Federal de Sergipe, campus São Cristóvão. Professor do mestrado PROFLETRAS-UFS. Doutor em Estudos Linguísticos pela UFF. Líder do grupo de pesquisa GEADAS (Grupo de Estudos Alfabetização, Discurso e Aprendizagens). Membro do GEPLA (Grupo de Estudos e Pesquisas em Linguística Aplicada).

ricardocarvalho.ufs@hotmail.com
} 